\title{
Design of catalytic metal-organic assemblies via shape complementarity and conformational constraints in dual curvature ligands
}

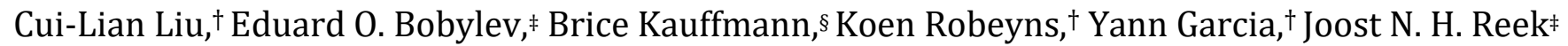 \\ and Michael L. Singleton*,†
}

${ }^{\dagger}$ Institute of Condensed Matter and Nanosciences, Université catholique de Louvain, Place Louis Pasteur 1, Louvain-laNeuve, 1348, Belgium.

¥Van 't Hoff Institute for Molecular Sciences, University of Amsterdam, Science Park 904, Amsterdam 1098 XH, The Netherlands.

§Universite' de Bordeaux CNRS, INSERM, UMS3033, Institut Europe'en de Chimie et Biologie (IECB), 2 rue Robert Escarpit, 33600 Pessac, France

ABSTRACT: Non-covalent interactions play an essential role in the folding and self-assembly of large supramolecular biolog-
ical assemblies in nature. These interactions are not only a driving force for the formation of large structures but also control
conformation and complementary shapes of subcomponents that promote the diversity of structures and functions of the
resulting assemblies. Understanding how non-covalent interactions direct self-assembly and the effect of conformation and
complementary shapes on self-assembled structures will help design artificial supramolecular systems with extended com-
ponents and functions. Herein, we develop a strategy for controlling more complex self-assembly with lower symmetry and
flexible building blocks that combine endohedral non-covalent interactions with a dual curvature in the ligand backbone to
give additional shape complementarity. A Diels-Alder reaction was used to break the symmetry of the diazaanthracene units
of the ligands to give dual curvature ligands with different shapes and endohedral groups (L1-L3). The self-assembly studies
of these ligands demonstrated that non-covalent interactions and shape complementary effectively control the self-assembly
and enable the design of cages for supramolecular catalysis.

\section{Introduction}

Self-assembly and folding play essential roles in the complexity and function of proteins. For example, these processes in enzymes lead to the formation of active site cavities lined with functional groups that promote the range of reactions necessary for life. ${ }^{1}$ Over the past decades, the possibility of generating synthetic molecules with similar complexity and functions has inspired significant progress in designing self-assembled cavitands. ${ }^{2}$ While numerous strategies for the self-assembly of such structures have been developed, the combination of organic ligands and metal ions for the formation of metal-organic architectures has risen as a highly promising approach. ${ }^{3}$ Notably, the combination of $\mathrm{Pd}^{2+}$ or $\mathrm{Pt}^{2+}$ with ditopic ligands for the formation of $\mathrm{M}_{\mathrm{n}} \mathrm{L}_{2 \mathrm{n}}$ structures has attracted substantial attention and led to some of the largest well-defined systems. ${ }^{4} \mathrm{~A}$ wide range of applications related to their cavities has been reported, including sensing, catalysis, drug delivery, storage, and molecular recognition. ${ }^{5}$

Unlike synthetic building blocks, folding of peptides leads to subunits for self-assembly that have not only complex electrostatic potential surfaces but also a wide diversity of shapes. ${ }^{6}$ The resulting high complementarity between different subcomponents allows for the selective self-assembly of different units into complex asymmetric architectures. By contrast, the majority of synthetic strategies for coordination-driven self-assembly rely on rigid ligands with high, often planar, symmetry. ${ }^{7}$ This can be readily seen in
$\mathrm{M}_{n} \mathrm{~L}_{2 n}$ assemblies. The ligands are most commonly curved organic molecules where $\mathrm{N}$-heterocyclic donor groups are connected by flat aromatic or alkyne spacers, the rigidity of which allows the angle between coordination sites, the bend angle, to be well-defined. ${ }^{4 b, 8}$ This offers numerous advantages, such as allowing good prediction of the final selfassembled structures and clean formation of single species. Still, the use of lower symmetry ligands could allow additional shape complementarity between ligands to help direct self-assembly, ultimately leading to new design strategies and more complex structures..$^{9}$ In the last decade, a number of elegant approaches relying on enhanced shape complementarity for controlling self-assembly have been described, such as combining two different ditopic ligands with compatible convergent and divergent bend angles or the use of coordination sphere engineering. ${ }^{10}$ The latter uses additional functional groups included near the coordination sites on the ligands to provide complementarity interligand steric or electrostatic interactions. ${ }^{11}$

Recently, we succeeded in using heteroaromatic amidebased ligands for the self-assembly of multiple $\operatorname{Pd}_{n} \mathrm{~L}_{2 n}(\mathrm{n}=2$, 6 , or 12) metal-organic cages capable of neutral guest discrimination. ${ }^{12}$ Despite the flexibility around the amide bonds, non-covalent interactions in the ligands lead to preferential curved conformational states that orient the coordination sites and allow sufficient control over the bend angles of the ligands to direct self-assembly. Nevertheless, these ligands are predominately flat and offer only limited 
interactions between ligands for the self-assembly of metalorganic cages. In fact, this is seen in the majority of ligands used for the self-assembly of $M_{n} L_{2 n}$ assemblies. ${ }^{4}$ Modification of the surface of the flat aromatic units to include perpendicular interactions is a challenge. However, this can be the fastest way to direct groups towards other ligands for designing interligand interactions and shape complementarity. We have recently shown that the large diazaanthracene units used for our ligands are amenable to modification via Diels-Alder reaction leading to diazaiptycene or triptycene units. ${ }^{13}$ These motifs are intriguing for incorporating additional shape complementary aspects, remote from the coordination sites, into heteroaromatic amide ligands for selfassembly. In effect, the reaction of the central ring in the diazaanthracene bends the attached $\mathrm{N}$-heterocyclic rings towards each other, a change which, in the ligand structure, would add an additional curvature perpendicular to the curvature that defines the bend angle, Figure 1a. Herein, we demonstrate that this dual curvature, combined with the electrostatic interactions that dictate the bend angle, can direct self-assembly towards a single $\mathrm{M}_{2} \mathrm{~L}_{4}$ cage or $\mathrm{M}_{4} \mathrm{~L}_{8}$ double-walled metallomacrocycle out of the hundreds of possi- ble stereoisomers that could result from different combinations of amide conformation and triptycene unit orientation, Figures 1 and S9. Using this strategy, we further show that the high modularity of the amide ligands allows ready access to deep endohedral functionalized cavitands capable of tandem catalysis.

\section{Results and Discussion}

Ligand design and synthesis - Diazatriptycene ligands $\mathbf{L} 1$ and $\mathbf{L} 2$ were synthesized in three steps, Scheme 1, starting with a [4+2] cycloaddition between in situ generated benzyne and a functionalized 1,8-diazaanthracene-2,7-dicarboxylate ester. Subsequent saponification and amide coupling with either 3-aminopyridine or 4-aminopyridine gave ligands L1 and L2 in 68 and 87\% yield, respectively. The Diels-Alder reaction with benzyne bends the ligands introducing the second curvature of $\sim 120^{\circ}$ between the planes of the amide groups based on the calculated structures, Figure 1a. Additionally, it adds a large benzene ring on one face of the ligand, which is expected to act as a source of steric bulk between ligands that can help control the selfassembly. a)

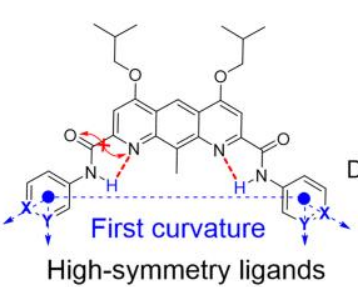

c)

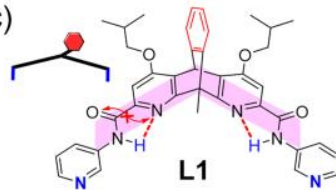

d)

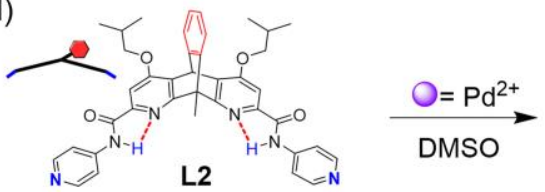

e)

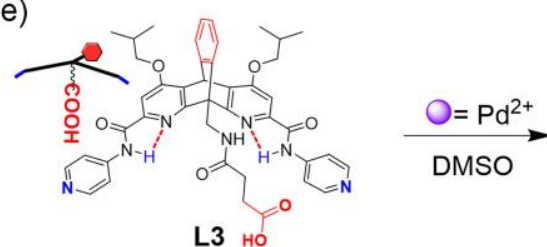

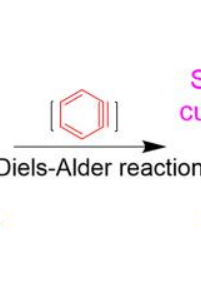

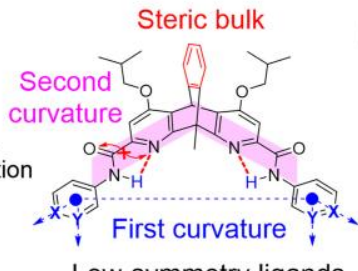

Low-symmetry ligands

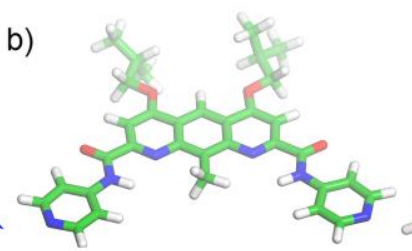

Flat versus dual curvature ligands
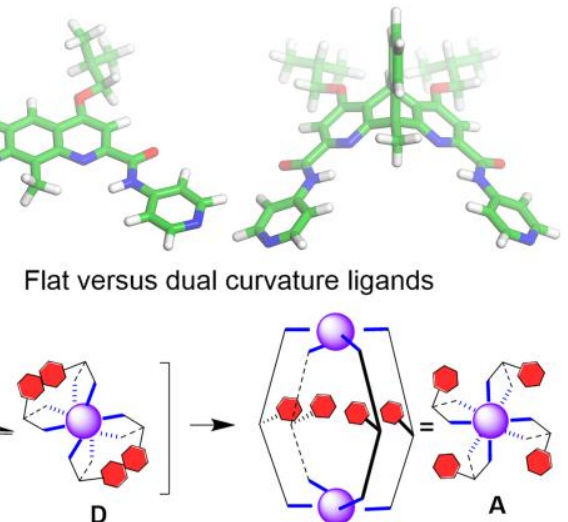

C

D

Isomers

A
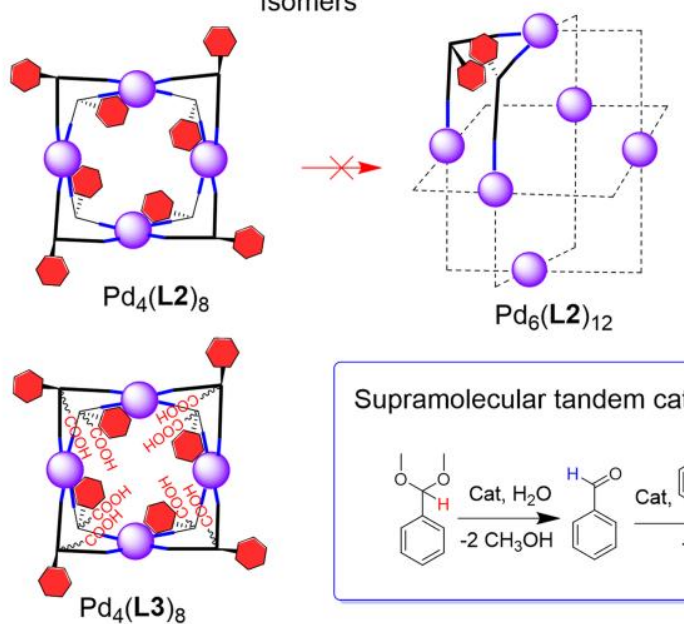

Supramolecular tandem catalysis

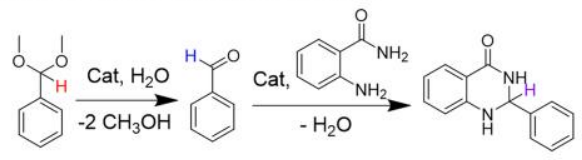

$\mathrm{Pd}_{2}(\mathbf{L} 1)_{4}$

Figure 1 a) Design of aromatic amide-based dual curvature ligands for coordination-driven self-assembly via Diels-Alder reaction with diazaanthracenes. This breaks the ligand symmetry and introduces additional shape complementarity as seen in the density functional theory (DFT) calculated structures of b) flat versus dual curvature ligands. c-e) the structure of ligands L1-L3 and their self-assembled products that can act as catalysts for the tandem reaction sequence shown in the inset. 


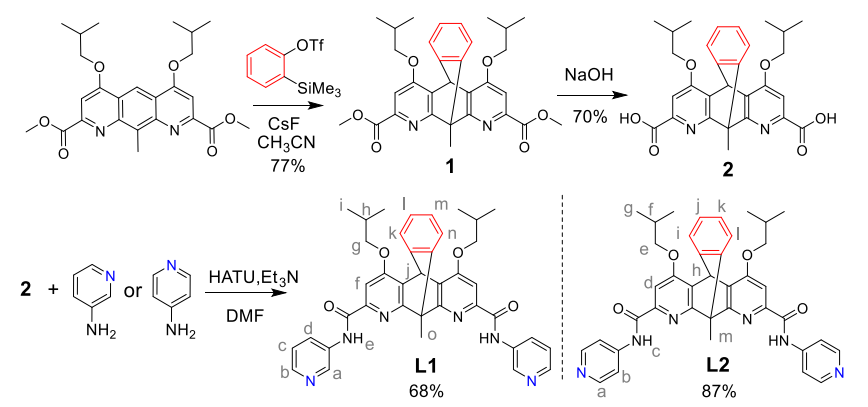

Scheme 1. Synthetic procedures for ligands L1and L2.

Self-Assembly with $\mathrm{L} 1$ and $\mathrm{L2}$ - Complexation of L1 with $\mathrm{Pd}^{2+}\left(\mathrm{NO}_{3}^{-}, \mathrm{BF}_{4}^{-}, \mathrm{CF}_{3} \mathrm{SO}_{3}^{-}\right.$, or $\mathrm{PF}_{6}^{-}$salt $)$in a 2:1 molar ratio in $\mathrm{CD}_{3} \mathrm{CN}$ or $\mathrm{D}_{7}-\mathrm{DMF}$ at $40^{\circ} \mathrm{C}$ results in a clear yellow solution. The ${ }^{1} \mathrm{H}$ NMR spectrum shows after two hours a single sharp set of signals with the same number of resonances as the starting ligand, Figure 2a-b and Figure S4-S6. Compared to L1, significant shifts of several resonances are observed. Notably, protons $\mathrm{H}_{a}$ and $\mathrm{H}_{\mathrm{b}}$ of the pyridine groups appear further downfield, implying coordination of pyridine to $\mathrm{Pd}(\mathrm{II})$. These observations suggest the formation of a single symmetric species derived from the complexation of $\mathbf{L 1}$ with $\mathrm{Pd}^{2+}$ ions. Based on the expected parallel coordination vectors of the ligand, this was proposed to be an $\mathrm{M}_{2} \mathrm{~L}_{4}$ structure. Consistent with this, diffusion-ordered ${ }^{1} \mathrm{H}$ NMR (DOSY) showed that all the proton resonances had the same diffusion coefficient of $D=6.99 \times 10^{-10} \mathrm{~m}^{2} / \mathrm{s}$, which, based on the Stokes-Einstein equation, indicates a small structure with a radius of $8.3 \AA$, Figure 2c. Electrospray ionization time-of-flight mass spectrometry (ESI-TOF-MS) further supported this assignment; a series of isotopic patterns corresponding to $\left[\mathrm{Pd}_{2}(\mathbf{L 1})_{4}\left(\mathrm{BF}_{4}\right)_{4-n}\right]^{\mathrm{n}+}(\mathrm{n}=2-4)$ were observed, Figure 2d.
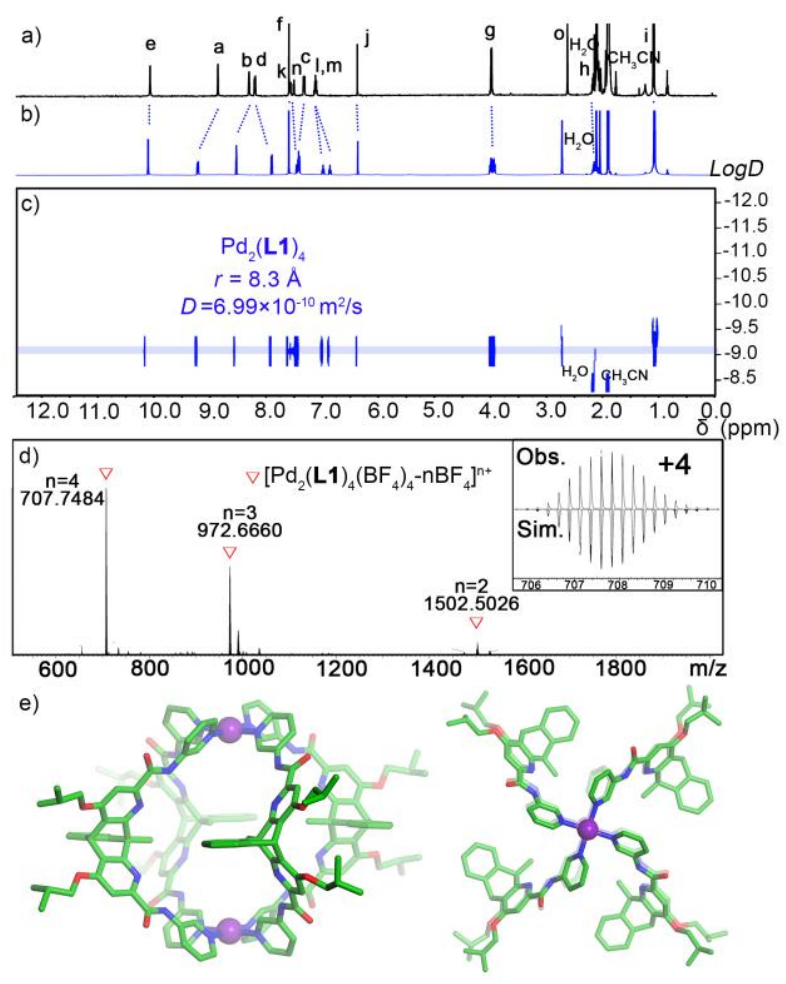

Figure 2. ${ }^{1} \mathrm{H}$ NMR spectra ( $\left.500 \mathrm{MHz}, \mathrm{CD}_{3} \mathrm{CN}, 298 \mathrm{~K}\right)$ of ${ }^{1} \mathrm{H} \mathrm{NMR}$ spectra of a) $\mathbf{L 1}$ and b) its self-assembly product $\mathrm{Pd}_{2}(\mathbf{L 1})_{4}$. c) the DOSY spectra of $\mathrm{Pd}_{2}(\mathbf{L 1})_{4}$. d) ESI-TOF-MS for $\mathrm{Pd}_{2}(\mathbf{L 1})_{4}$ as its $\mathrm{BF}_{4}{ }^{-}$salt. Inset shows the comparison of the observed isotopic pattern with the simulated spectrum. e) X-ray crystal structure of $\mathrm{Pd}_{2}(\mathbf{L 1})_{4}$ with views perpendicular to (left) and along (right) the Pd-Pd axis. Protons, solvent molecules and counterions are omitted for clarity.

For this species, the symmetry and single set of signals observed by NMR are interesting because the different orientations of the amides or ligand backbones could lead to hundreds of possible isomers, Figure 3 and Figure S8-S9. These nevertheless appear to converge to a single stable species, and time-dependent NMR studies of the self-assembly of L1 did not show any clear signs of other isomers forming as intermediates, Figure S5. Within ten minutes of mixing the ligand with $\mathrm{Pd}^{2+}$ ions, the ${ }^{1} \mathrm{H}$ NMR of the solution exhibited relatively broad signals with low intensity. ESI-TOFMS analysis of the solution mainly found $\mathrm{Pd}_{2}(\mathbf{L} \mathbf{1})_{4}\left(\mathrm{BF}_{4}\right)_{4}$ suggesting the composition of this mixture was predominately the $\mathrm{M}_{2} \mathrm{~L}_{4}$ cage with possibly some oligomers and intermediates from the self-assembly. After one hour, only a single sharp set of resonances, as observed above, emerges and becomes the significant species by ${ }^{1} \mathrm{H}$ NMR.

a) Conformations of $\mathbf{L 1}$

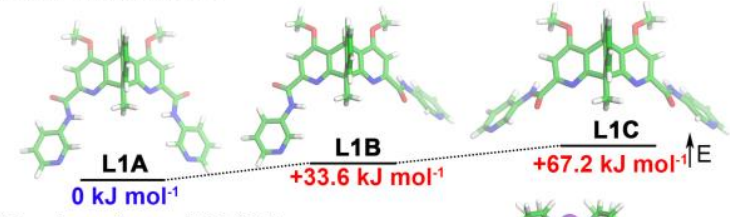

b) Conformations of $\mathrm{Pd}_{2}(\mathbf{L} \mathbf{1})_{4}$
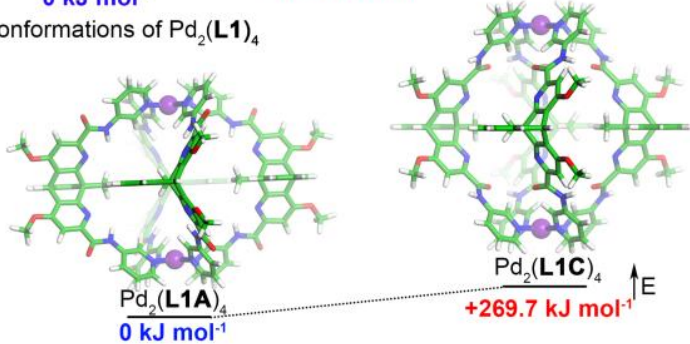

c) Isomers of $\mathrm{Pd}_{2}(\mathbf{L} 1)_{4}$

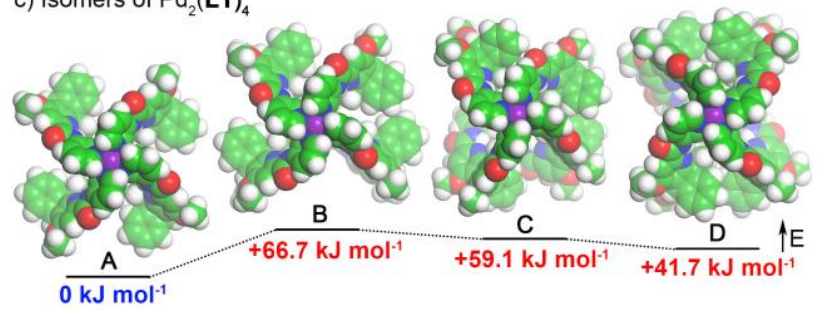

Figure 3. Density functional theory (DFT) calculated structures and relative energies(B3LYP/6-31g* for ligands and B3LYP/def2SVP for cages) of a) three possible conformations of ligand $\mathbf{L 1}(\mathbf{L 1 A}, \mathbf{L 1 B}$ and $\mathbf{L 1 C})$, b) $\mathrm{Pd}_{2}(\mathbf{L 1})_{4}$ cage with two representative ligand conformations, and c) four possible steric isomers of $\mathrm{Pd}_{2}(\mathbf{L} 1)_{4}$ cage

Relative to the possibility for different conformations, density functional theory (DFT) computational studies (B3LYP/6-31g*) support that the anti-conformation(L1A) between the amides of ligand $\mathbf{L 1}$ (possible ligand isomers, L1A, L1B, and L1C) should be favored by almost $30 \mathrm{~kJ} / \mathrm{mol}$ in the self-assembly solvent $\left(\mathrm{CH}_{3} \mathrm{CN}\right)$, Figure 3a. Similar studies (B3LYP/def2SVP ) on the $\mathrm{M}_{2} \mathrm{~L}_{4}$ cage also suggest that this preference should be maintained in the complex, 
Figure $3 \mathrm{~b}$. Still, the lack of planar symmetry in the ligands could result in four different $\mathrm{Pd}_{2}(\mathbf{L 1})_{4}$ isomers (A-D) with different cis/trans relationships between the 9,10-bridging groups, Figure 3c. However, the dual curvature designed into the ligands should allow for good shape complementarity that directs single isomer formation in order to avoid steric interactions between neighboring ligands. Indeed, additional DFT studies comparing the four isomers estimated that isomer A, where the curves of the ligands are oriented in the same direction, should be the most stable by $\sim 40$ $\mathrm{kJ} / \mathrm{mol}$. Based on the calculated structures, the higher energy for the three other isomers likely results from steric interactions between nearby benzene rings in the diazatriptycene backbones.

Further support for the formation of isomer A came from its solid-state structure. Single crystals of $\mathrm{Pd}_{2}(\mathbf{L 1})_{4}\left(\mathrm{BF}_{4}\right)_{4}$ could be obtained and were studied by X-ray diffraction, Figure 2e. The crystal structure of the complex shows two palladium ions, each in a square planar $\mathrm{N}_{4}$ coordination environment, bridged by four units of $\mathbf{L 1}$ with a $\mathrm{Pd}^{2+}$ to $\mathrm{Pd}^{2+}$ distance in the cage of $12.3 \AA$. In accordance with the solution observations and computational results, the benzene rings on the ligands are all oriented in the same direction around the four-fold symmetry axis, and the amide carbonyls are all anti to the endocyclic nitrogens of the diazatriptycene units. Relative to our previously reported $\mathrm{M}_{2} \mathrm{~L}_{4}$ cage, ${ }^{12}$ which had overall $\mathrm{D}_{4 \mathrm{~h}}$ symmetry, the directionality of the triptycene units used for $\mathrm{Pd}_{2}(\mathbf{L 1})_{4}$ leads to a decrease in the symmetry of the cage to $\mathrm{C}_{4 \mathrm{~h}}$.

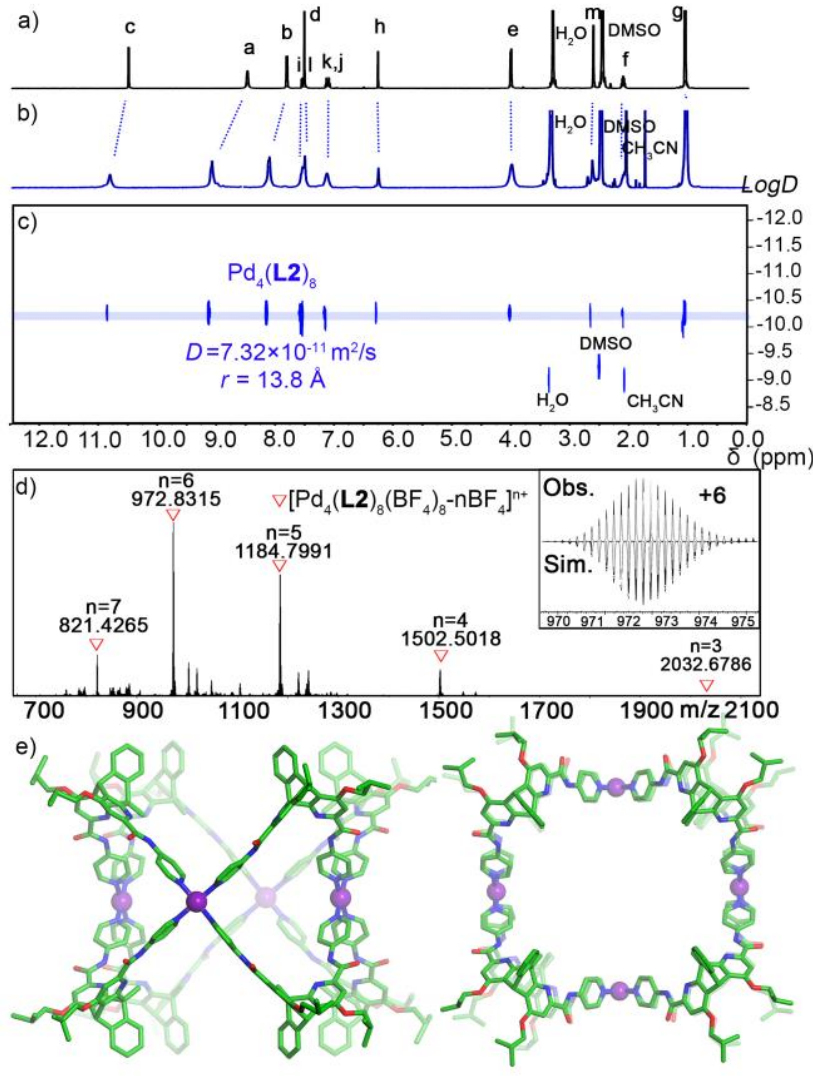

Figure 4. ${ }^{1} \mathrm{H}$ NMR spectra (500 MHz, DMSO- $\left.d_{6}, 298 \mathrm{~K}\right)$ of ${ }^{1} \mathrm{H}$ NMR spectra of a) $\mathbf{L} 2$ and b) its self-assembly product $\mathrm{Pd}_{4}(\mathbf{L 2})_{8}$. c) the DOSY spectra of $\mathrm{Pd}_{4}(\mathbf{L} 2)_{8}$. d) ESI-TOF-MS for $\mathrm{Pd}_{4}(\mathbf{L} 2)_{8}$ as its $\mathrm{BF}_{4}^{-}$salt. Inset shows the comparison of the observed isotopic pattern with the simulated spectrum. e) X-ray crystal structure of $\mathrm{Pd}_{4}(\mathbf{L} 2)_{8}$ with side (left) and top (right) views. Protons, solvent molecules and counterions are omitted for clarity.

Motivated by the high selectivity observed with ligand L1, we next looked to see if the self-assembly of larger structures using the reduced symmetry ligands could still be controlled by the dual curvature effects. Ligand $\mathbf{L} 2$ was reacted with 0.5 equivalents of $\mathrm{Pd}^{2+}\left(\mathrm{NO}_{3}^{-}, \mathrm{BF}_{4}^{-}, \mathrm{CF}_{3} \mathrm{SO}_{3}^{-}\right.$, or $\mathrm{PF}_{6}^{-}$salt $)$ in $\mathrm{D}_{6}$-DMSO or $\mathrm{D}_{7}$-DMF. Similar to self-assembly with L1, the ${ }^{1} \mathrm{H}$ NMR spectrum showed a single set of resonances distinct from the starting ligand, Figure $4 a-b$ and Figure S10-S12. As expected, DOSY studies on this species suggested the formation of a larger structure $\left(D=7.32 \times 10^{-11} \mathrm{~m}^{2} / \mathrm{s} ; r=13.8 \AA\right.$ ), Figure 4c. However, as opposed to the $\mathrm{M}_{6} \mathrm{~L}_{12}$ or $\mathrm{M}_{12} \mathrm{~L}_{24}$ cages obtained previously with the analogous planar ligand. ${ }^{12}$ ESI-TOF-MS analysis showed isotopic patterns consistent with the formation of an $\mathrm{M}_{4} \mathrm{~L}_{8}$ assembly with the formula $\mathrm{Pd}_{4}(\mathbf{L} 2)_{8}\left(\mathrm{BF}_{4}\right)_{8}$, Figure $4 \mathrm{~d}$. This composition was further confirmed by X-ray diffraction studies. The crystal structure shows a deep crown-like double-walled metallomacrocycle, Figure 4e. The four palladium ions are found in the same plane and can be seen as occupying the four corners of a square. Each palladium has square-planar coordination, with two ligands, one above and one below the plane, bridging between each pair of adjacent metal ions. This gives a structure with cavity dimensions of $20.5 \AA$ between opposite palladiums and $23.8 \AA$ between the top and bottom faces. All of the ligands are oriented in the same way, with the benzene ring of the diazatriptycene units in each bridging pair pointing away from each other towards either the top or bottom of the structure. This also results in the 9position group on the diazatriptycene units of the ligands converging towards the center of the cavity.

Interestingly, the bend angle for the ligands in the crystal structure of $\operatorname{Pd}_{4}(\mathbf{L} 2)_{8}$ is $\sim 70^{\circ}$, while the same bend angle in the DFT optimized structure of the free ligands was found to be $\sim 60^{\circ}$. Previously, we observed that the partial flexibility in the amide bonds could allow changes of almost $30^{\circ}$ in the bend angle, making it possible to transition from a smaller cage structure to a larger one. ${ }^{12}$ For example, $\mathrm{M}_{6} \mathrm{~L}_{12}$ and $\mathrm{M}_{12} \mathrm{~L}_{24}$ structures, which require ideal bend angles around $90^{\circ}$ and $120^{\circ}$ respectively, could be formed with the same aromatic amide ligand in a step-wise manner. With this in mind, we attempted to push the self-assembly of $\mathrm{Pd}_{4}(\mathbf{L} 2)_{8}$ towards a larger $\mathrm{Pd}_{6}(\mathbf{L} 2)_{12}$ octahedron. However, even after extending the time for self-assembly up to two weeks or increasing the temperature to $120^{\circ} \mathrm{C}$, no other apparent species were observed by NMR nor ESI-TOF-MS analysis. The cube-like structures in most $\mathrm{M}_{6} \mathrm{~L}_{12}$ octahedra contain eight adjacent 3-fold symmetry axes. With the dual curvature ligand $\mathbf{L} \mathbf{2}$, it is impossible for the ligands to be arranged in a way where they are all pointing away from each other, something that can occur with $\mathrm{Pd}_{4}(\mathbf{L} 2)_{8}$, Figure 4e. Interestingly, no close contacts of the complementary shapes, as seen in the isomers of $\mathrm{Pd}_{2}(\mathbf{L 1})_{4}$, are observed in a PM6 model of a $\operatorname{Pd}_{6}(\mathbf{L} 2)_{12}$ octahedron, Figure S13. Thus, it is suspected that a combination of unfavorable ligand orientation and significant distortions in the torsion angles around the amides necessary to form the $\mathrm{M}_{6} \mathrm{~L}_{12}$ structure may limit its stability. 
Self-Sorting Studies - To look at how strongly the noncovalent interactions present in the ligand structures control their bend angle, self-sorting studies were performed. In theory, changes in the torsion angles around the amides, at the expense of weakening the non-covalent interactions, should permit both ligands to achieve the same bend angles. While this could potentially allow the self-assembly of structures containing both ligands $\mathbf{L} \mathbf{1}$ and $\mathbf{L 2}$, this does not appear to be favored. Indeed, upon reacting a 1:1 mixture of $\mathbf{L 1}$ and $\mathbf{~} 2$ with $\mathrm{Pd}\left(\mathrm{CH}_{3} \mathrm{CN}\right)_{4}\left(\mathrm{BF}_{4}\right)_{2}$ in $\mathrm{D}_{7}-\mathrm{DMF}$, two distinct sets of signals, as verified by the COSY and DOSY spectra, were observed by ${ }^{1} \mathrm{H} \mathrm{NMR}$, corresponding to the $\mathrm{M}_{2}(\mathbf{L} \mathbf{1})_{4}$ and $\mathrm{M}_{4}(\mathbf{L} 2)_{8}$ species as described above, Figure 5 and Figure S17. ESI-TOF-MS analysis also showed only a mixture of $\mathrm{M}_{2} \mathrm{~L}_{4}$ and $\mathrm{M}_{4} \mathrm{~L}_{8}$ species. These observations indicate that, despite the weak nature of the non-covalent interactions that direct the ligand conformation, they still provide sufficient control to allow self-sorting based on bend angle, something only previously reported for more ridged ligands. ${ }^{14}$

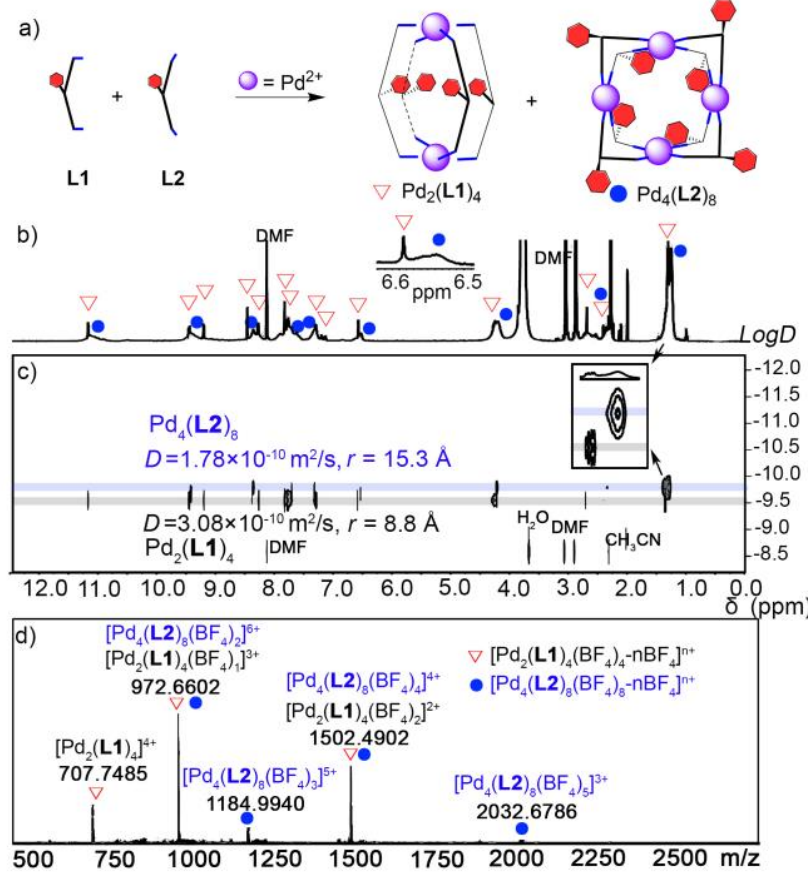

Figure 5. a) Narcissistic self-sorting of $\mathrm{M}_{2} \mathrm{~L}_{4}$ and $\mathrm{M}_{4} \mathrm{~L}_{8}$ architectures from mixed ligands. b) ${ }^{1} \mathrm{H}$ NMR spectra (500 MHz, DMF$d 7,298 \mathrm{~K}), \mathrm{c}$ ) the DOSY spectra and d) ESI-TOF-MS of self-sorting outcomes showing a mixture of $\mathrm{M}_{2}(\mathbf{L 1})_{4}$ and $\mathrm{M}_{4}(\mathbf{L 2})_{8}$ species.

Cage functionalization and catalysis - While the smaller cavity in $\operatorname{Pd}_{2}(\mathbf{L 1})_{4}$ limits the potential for having both endohedral functionalization and guest binding, the larger $\mathrm{M}_{4} \mathrm{~L}_{8}$ structure is an intriguing scaffold for designing functional group lined cavities for catalysis. From the structure, the large openings in the top and bottom faces of the host can easily allow substrate and product diffusion in or out of the deep cavity. Moreover, the defined orientation of the diazaanthracene 9-position and modularity of the ligand design can facilitate the endohedral functionalization of the structure. To this end, ligand L3 bearing a carboxylic acid function of high interest for self-assembly of functional supramolecular catalysts was synthesized as shown in Scheme 2. Following reported procedures, the 9-methyl in the precursor 1,8-diazaanthracene-2,7-dicarboxylate ester could be easily functionalized into a Boc-protected 9-methylamino diazaanthracene derivative. ${ }^{15}$ Next, triptycene formation and installation of the pyridine coordination sites were performed in a manner analogous to L2. Subsequent amine deprotection and reaction with succinic anhydride allowed the incorporation of the carboxylic acid group in L3.

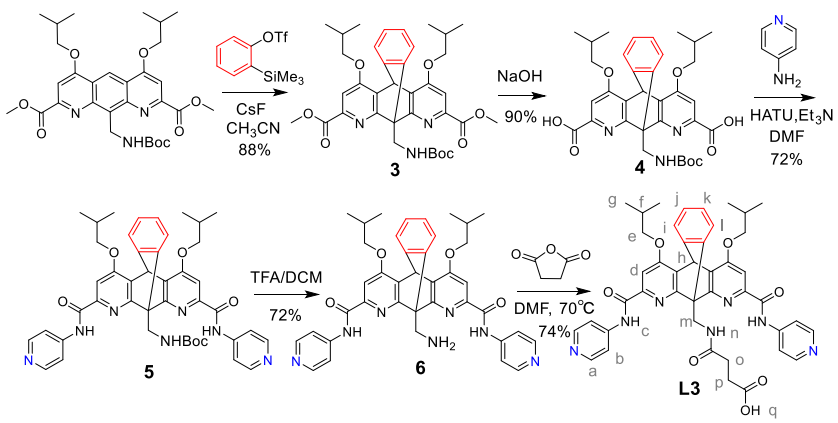

Scheme 2 Synthetic procedures for ligand L3.
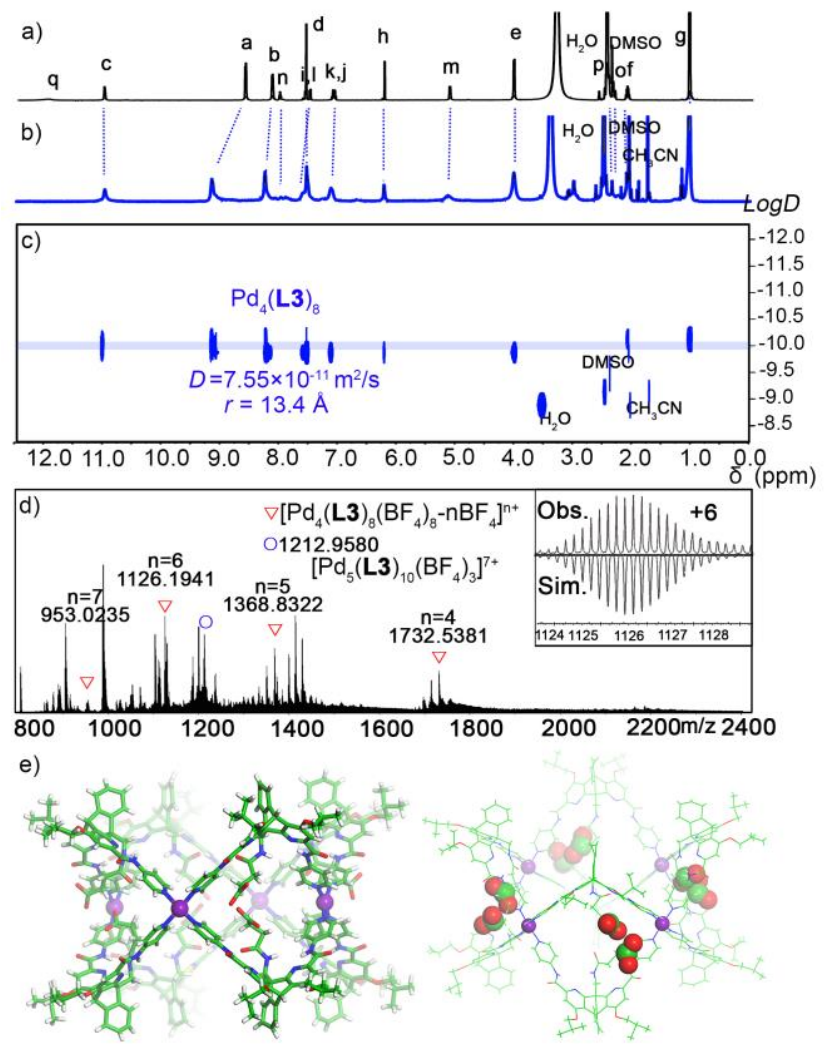

Figure 6. ${ }^{1} \mathrm{H}$ NMR spectra $\left(500 \mathrm{MHz}, \mathrm{DMSO}-d_{6}, 298 \mathrm{~K}\right)$ of ${ }^{1} \mathrm{H}$ NMR spectra of a) $\mathbf{L 3}$ and b) its self-assembly product $\mathrm{Pd}_{4}(\mathbf{L} 3)_{8}$. c) the DOSY spectra of $\mathrm{Pd}_{4}(\mathbf{L 3})_{8}$. d) ESI-TOF-MS for $\mathrm{Pd}_{4}(\mathbf{L} 3)_{8}$ as its $\mathrm{BF}_{4}^{-}$salt. Inset shows the comparison of the observed isotopic pattern with the simulated spectrum. e) X-ray crystal structure of $\mathrm{Pd}_{4}(\mathbf{L} 3)_{8}$ with side views (left) and highlight the 9position endohedral carboxylic acids (right). Solvent molecules and counterions are omitted for clarity.

Despite potential for the endohedral carboxylic acid to compete with metal-pyridine interactions, ${ }^{3 b, 16}$ self-assembly with $\mathbf{L} 3$ proceeded without any problems. Upon reaction of $\mathbf{L 3}$ with $\mathrm{Pd}^{2+}\left(\mathrm{NO}_{3}^{-}, \mathrm{BF}_{4}^{-}, \mathrm{CF}_{3} \mathrm{SO}_{3}^{-}\right.$, or $\mathrm{PF}_{6}$ salt $)$, in a $2: 1$ molar ratio in $\mathrm{D}_{6}$-DMSO or $\mathrm{D}_{7}-\mathrm{DMF}$, similar changes as for 
self-assembly with $\mathbf{L 2}$, i.e., a single set of signals shifted relative to the free ligand, are seen by ${ }^{1} \mathrm{H}$ NMR, Figure 6a-b and Figure S14-S16. Given the similar bend angles expected for L2 and L3, self-assembly with the functionalized ligand should also lead to an $\mathrm{M}_{4} \mathrm{~L}_{8}$ structure. This was supported by DOSY studies $\left(D=7.55 \times 10^{-11} \mathrm{~m}^{2} / \mathrm{s} ; r=13.4 \AA\right)$, which suggested the formation of a complex with a size similar to parent $\mathrm{Pd}_{4}(\mathbf{L 2})_{8}$, Figure 6c. The $\mathrm{Pd}_{4}(\mathbf{L 2})_{8}\left(\mathrm{BF}_{4}\right)_{8}$ formula was further confirmed by ESI-TOF-MS, though some low-intensity signals for an $\mathrm{M}_{5} \mathrm{~L}_{10}$ structure could also be observed, Figure $6 \mathrm{~d}$. The presence of the more bulky group on the 9position of $\mathbf{L} 3$ relative to $\mathbf{L} \mathbf{2}$ may lead to this minor formation of some of the larger macrocycles. ${ }^{17}$ Still, the X-ray crystal structure of the product showed $\mathrm{Pd}_{4}(\mathbf{L} 3)_{8}$ and was highly similar to the $\mathrm{M}_{4}(\mathbf{L} 2)_{8}$ structure, Figure 6e. The 9-position substituents are still found pointing into the cavity and oriented towards each other such that they occupy the cavity windows formed by the pairs of bridging ligands. This also leads to short distances between neighboring carboxylic acid groups ( 0 -0 distances of $2.3-2.7 \AA$ ) , suggesting potential hydrogen bond formation between these groups. Such interactions might be expected to lead to some preference for self-sorting. However, self-assembly with mixtures of $\mathbf{L} 3$ and $\mathbf{L} 2$ resulted in statistical mixtures of $\mathrm{M}_{4} \mathrm{~L}_{8}$ species with different ratios of the two ligands, though similar studies using $\mathbf{L} 3$ and $\mathbf{L 1}$ still showed self-sorting into $\mathrm{M}_{2}(\mathbf{L 1})_{4}$ and $\mathrm{M}_{4}(\mathbf{L} 3)_{8}$ based on the different bend angles, Figure 7 and Figure S18-S21.

a)
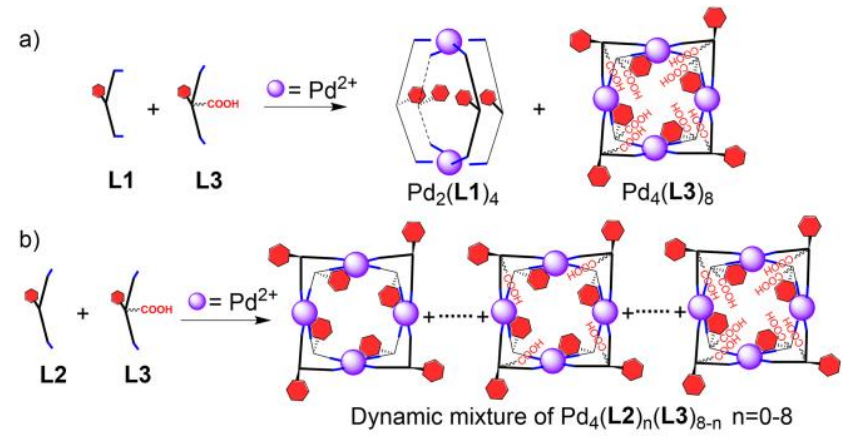

Figure 7. Mixed ligands self-assembly with ligand L3, mixed with a) $\mathbf{L 1}$ leads to narcissistic self-sorting of $\mathrm{M}_{2}(\mathbf{L 1})_{4}$ and $\mathbf{M}_{4}(\mathbf{L 3})_{8}$ assemblies and b) $\mathbf{L} 2$ formed non-sorted scrambled dynamic mixtures of $\mathrm{Pd}_{4}(\mathbf{L 2})_{\mathrm{n}}(\mathbf{L} 3)_{8-\mathrm{n}}\left(\mathrm{BF}_{4}\right)_{8}, \mathrm{n}=0-8$.

Metal-organic architectures offering defined microenvironments for specific host-guest interactions are of interest for developing enzyme active site mimics. The confined spaces in these structures have been reported to give significant rate enhancements and product selectivity for a range of organic reactions..$^{5 f, 18}$ Based on the carboxylic acid functions in ligand $\mathbf{L 3}$, we were interested in studying the reactivity of the endohedral functionalized $\mathrm{M}_{4} \mathrm{~L}_{8}$ structures. For this, we chose to look at a tandem reaction sequence involving hydrolysis of the dimethyl acetal of benzaldehyde followed by aminal formation with anthranilamide to give 2,3dihydroquinazolinones. This class of molecules is a useful privileged scaffold in medicinal chemistry due to their range of pharmacological activities. ${ }^{19}$ Importantly, both steps of the reaction sequence can be catalyzed by either Lewis or Bronsted acids, and the latter step was also reported to be highly efficient with rate enhancements inside the cavity of metal-organic cages. ${ }^{20}$ These make the endohedral acid functionalization in the $\mathrm{Pd}_{4}(\mathbf{L} 3)_{8}$ and the parent $\mathrm{Pd}_{4}(\mathbf{L} 2)_{8}$ structures highly interesting as potential supramolecular catalysts for promoting product formation, Table 1.

Table 1. Supramolecular catalysis at room temperature

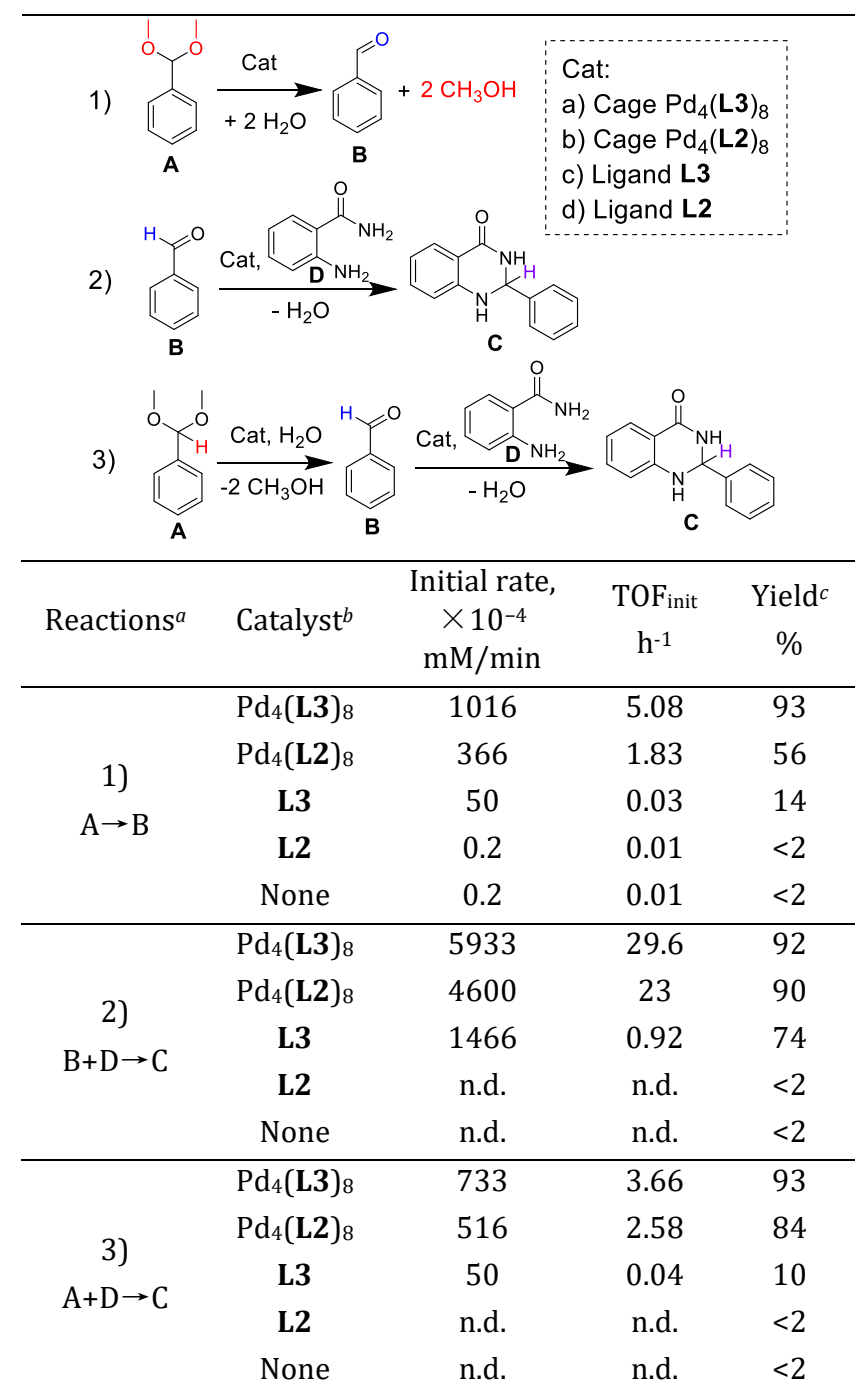

${ }^{a}$ [substrate] $=40 \mathrm{mM} ;{ }^{b} 3.1 \mathrm{~mol}_{0} \mathrm{Pd}_{4}(\mathbf{L} 3)_{8}$ or $\mathrm{Pd}_{4}(\mathbf{L} 2)_{8}$, or $24.8 \mathrm{~mol} \% \mathbf{L} 3$ or $\mathbf{L} 2$ as a catalyst; $c$ NMR Yield deterimined at $t=24 \mathrm{~h}$; n.d. = not able to be deterimined due to no visible product signals; Initial rates and $\mathrm{TOF}_{\text {init }}$ were calculated based on the first four hours of reaction

The assemblies, $\mathrm{Pd}_{4}(\mathbf{L} 3)_{8}$ or $\mathrm{Pd}_{4}(\mathbf{L} 2)_{8}$, or the free ligands L3 or L2 as controls, were used as catalysts for the tandam 2,3-dihydroquinazolinones synthesis (reaction 3, Table 1) as well as the individual acetal hydrolysis (reaction 1, Table 1) and aminal formation steps (reaction 2, Table 1) separately. In all cases, the reactions were performed in wet DMSO using the substrates at concentrations of $\sim 40 \mathrm{mM}$ in the presence of either $3.1 \mathrm{~mol}_{0} \mathrm{Pd}_{4}(\mathbf{L} 3)_{8}$ or $\mathrm{Pd}_{4}(\mathbf{L} 2)_{8}$, or $24.8 \mathrm{~mol} \% \mathbf{L} \mathbf{3}$ or $\mathbf{L} \mathbf{2}$ as a catalyst and product formation was followed by ${ }^{1} \mathrm{H}$ NMR using an internal standard. The initial 
rates and TOF, as well as the yields for the reactions are summarized in Table 1 and Figures S22-S26.

In the absence of a catalyst or with only unfunctionalized $\mathbf{L 2}$, there is no appreciable reaction for any of the steps. Only for the acetal hydrolysis was minor product formation observed within the first four hours of reaction. Expectedly, the presence of the carboxylic acid group on L3 leads to a minor improvement in rection rates, with initial rates of 50 , 1466 , and $50 \times 10^{-4} \mathrm{mM} / \mathrm{min}$ calculated for reactions 1,2 , and 3 respectively. By contrast, more remarkable rate enhancements are observed with the self-assembled structures. Acetal hydrolysis to benzaldehyde in wet DMSO occurs rapidly with $\mathrm{Pd}_{4}(\mathbf{L} 3)_{8}$ at room temperature. The initial rate, $1016 \times 10^{-4} \mathrm{mM} / \mathrm{min}$, with the assembly represents an almost $2000 \%$ increase over the free $\mathbf{L} 3$. The same reaction with $\mathrm{Pd}_{4}(\mathbf{L 2})_{8}$, while also faster than the ligands is still about 2.8 times slower than the acid functionalized assembly. The stark difference between the two otherwise similar cages highlights the importance of the endohedral functionalization in $\mathrm{Pd}_{4}(\mathbf{L} 3)_{8}$ for this initial hydrolysis step. Nevertheless, the reactivity with $\mathrm{Pd}_{4}(\mathbf{L} 2)_{8}$ suggests that the $\mathrm{Pd}^{2+}$ ions in the two structures can potentially act as Lewis acids to catalyze the reaction. ${ }^{21}$ Indeed, this also appears to be the case for the aminal formation step, both $\mathrm{Pd}_{4}(\mathbf{L} 2)_{8}$ and $\mathrm{Pd}_{4}(\mathbf{L} 3)_{8}$ performed similarly, with rates $=4600$ and $5933 \times 10^{-4}$ $\mathrm{mM} / \mathrm{min}$ respectively, Table 1 and Figure S27-S31. L3, while moderately active for this step, was substantially slower than either $\mathrm{Pd}_{4}(\mathbf{L 2})_{8}$ and $\mathrm{Pd}_{4}(\mathbf{L} 3)_{8}$.

The trends for the individual steps are also seen for the tandem reaction of benzaldehyde dimethyl acetal with anthranilamide, Table 1 and Figure S32-S36. When $\mathrm{Pd}_{4}(\mathbf{L 3})_{8}$ was used as the catalyst, the starting acetal disappears rapidly. The initial rate was calculated to be $733 \times 10^{-4} \mathrm{mM} / \mathrm{min}$, representing a $1400 \%$ increase versus the free ligand. The same reaction with the $\mathrm{Pd}_{4}(\mathbf{L} 2)_{8}$ assembly lacking the carboxylic acid groups also leads to significant product formation. However, the intitial reaction rate, $516 \times 10^{-4}$ $\mathrm{mM} / \mathrm{min}$, is moderately slower than for $\mathrm{Pd}_{4}(\mathbf{L} 3)_{8}$, consistent with the results obtained for the individual steps of the reaction. Interestingly, for both cages, only minor amounts of the aldehyde were ever observed. While this can correspond with the slower kinetics of the hydrolysis step and formation of the aldehyde as being rate-limiting, the oxonium intermediate generated from loss of a methoxy group in the starting acetal can also react directly with anthranilamide, bypassing the aldehyde. As shown in Figure S37, spiking the reaction with excess water does not substantially increase the reaction rate relative to controls without the additional water, suggesting the mechanism may indeed pass through direct anthranilamide addition onto the oxonium, something that may be facilitated by the cavity of the structures.

In order to further examine the efficiency of the catalyst, the reactions with $\mathrm{Pd}_{4}(\mathbf{L} 3)_{8}$ were set up with different ratios of catalyst to the substrate. Increasing or decreasing the substrates by 10 -fold leads to different relative catalyst loadings of $0.31 \%, 3.1 \%$ and $31 \%$ versus substrate. For the acetal hydrolysis, as shown in Figure S38-S41, even with the lowest catalyst ratio, by ${ }^{1} \mathrm{H}$ NMR the starting acetal disappears almost completely within $24 \mathrm{~h}$, coinciding with $>90 \%$ for- mation of the product. For the tandem reaction of benzaldehyde dimethyl acetal with anthranilamide, the lower catalyst:substrate ratio $(0.31 \%)$ expectedly leads to a decrease in the reaction rate. Nevertheless, $>90 \%$ product yield is still observed within $48 \mathrm{~h}$.

\section{Conclusions}

In summary, we have provided an effective strategy for controlling self-assembly in more complex systems by combining endohedral non-covalent interactions in aromatic amides with additional shape complementarity brought by dual curvature ligands. A straight forward Diels-Alder strategy was used to break the symmetry of the ligands and incorporate additional steric constraints and complementary shapes. This allowed three dual curvature ligands (L1-L3) to be obtained. The self-assembly studies of the ligands showed the designed constraints are able to highly control the self-assembly of the ligands with $\mathrm{Pd}^{2+}$ towards a single $\mathrm{M}_{2} \mathrm{~L}_{4}$ cage or $\mathrm{M}_{4} \mathrm{~L}_{8}$ double-walled metallomacrocycle out of hundreds of possible isomers. Moreover, the non-covalent interactions provide sufficient control to allow narcissistic self-sorting based on bend angle in mixtures of the flexible ligands. Finally, we show that this strategy can be used to generate endohedrally acid-functionalized $\mathrm{M}_{4}(\mathbf{L} 3)_{8}$ structures with deep cavities that are able to perform tandem catalysis with significant rate enhancements. These results give promising new design strategies for coordinationdriven self-assembly and the formation of diversely functionalized cavities of interest for catalytic applications.

\section{ASSOCIATED CONTENT}

Supporting Information. Complete experimental procedures, additional spectra figures, and tables of NMR, ESI-TOF-MS, CIF and crystal data are described in the text.

\section{AUTHOR INFORMATION}

\section{Corresponding Author \\ *m.singleton@uclouvain.be}

The authors declare no competing financial interest.

\section{ACKNOWLEDGMENT}

This research was supported in part through the Concerted Research Action (ARC16/21-074) and the China Scholarship Council (pre-doctoral fellowships for C.-L.L.). Computational resources were provided by the supercomputing facilities of the Université catholique de Louvain (CISM/UCL) and the Consortium des équipements de Calcul Intensif en Fédération Wallonie Bruxelles (CPCI) funded by the Fond de la Recherche Scientifique de Belgique (F.R.S.-FNRS) under convention 2.5020.11. We thank Dr S. Ouk for his generous financial support through the Fondation Louvain. We also thank Dr. Gabriella Barozzino for help with NMR measurements.

\section{REFERENCES}

(1) (a) Heckmann, C. M.; Paradisi, F. ChemCatChem 2020, 12, 6082. (b) Drout, R. J.; Robison, L.; Farha, O. K. Coord. Chem. Rev. 2019, 381, 151. (c) Benkovic, S. J.; Hammes-Schiffer, S. Science 2003, 301, 1196.

(2) (a) Liu, Y.; Zhao, W.; Chen, C. H.; Flood, A. H. Science 2019, 365, 159. (b) Liu, Z.; Nalluri, S. K. M.; Stoddart, J. F. Chem. Soc. Rev. 2017, 46, 2459. (c) Kim, D. S.; Sessler, J. L. Chem. Soc. Rev. 2015, 44, 532. 
(d) Gil-Ramírez, G.; Leigh, D. A.; Stephens, A. J. Angew. Chem., Int. Ed. 2015, 54, 6110. (e) Lindoy, L. F.; Park, K.-M.; Lee, S. S. Chem. Soc Rev. 2013, 42, 1713. (f) Cook, T. R.; Zheng, Y.-R.; Stang, P. J. Chem. Rev. 2013, 113, 734. (g) Kondratuk, D. V.; Perdigao, L. M. A.; O'Sullivan, M. C.; Svatek, S.; Smith, G.; O'Shea, J. N.; Beton, P. H.; Anderson, H. L. Angew. Chem., Int. Ed. 2012, 51, 6696. (h) Tozawa, T.; Jones, J. T. A.; Swamy, S. I.; Jiang, S.; Adams, D. J.; Shakespeare, S.; Clowes, R.; Bradshaw, D.; Hasell, T.; Chong, S. Y.; Tang, C.; Thompson, S.; Parker, J.; Trewin, A.; Bacsa, J.; Slawin, A. M. Z.; Steiner, A.; Cooper, A. I. Nat. Mater. 2009, 8, 973. (i) MacGillivray, L. R.; Atwood, J. L. Nature $1997,389,469$.

(3) (a) Zou, Y.-Q.; Zhang, D.; Ronson, T. K.; Tarzia, A.; Lu, Z.; Jelfs, K. E.; Nitschke, J. R. J. Am. Chem. Soc. 2021, 143, 9009. (b) Percástegui, E. G.; Ronson, T. K.; Nitschke, J. R. Chem. Rev. 2020, 120, 13480. (c) Gosselin, A. J.; Rowland, C. A.; Bloch, E. D. Chem. Rev. 2020, 120, 8987. (d) Sun, Y.; Chen, C.; Stang, P. J. Acc. Chem. Res. 2019, 52, 802. (e) Saha, S.; Regeni, I.; Clever, G. H. Coord. Chem. Rev. 2018, 374, 1. (f) Cook, T. R.; Stang, P. J. Chem. Rev. 2015, 115, 7001.

(4) (a) Fujita, D.; Ueda, Y.; Sato, S.; Yokoyama, H.; Mizuno, N.; Kumasaka, T.; Fujita, M. Chem 2016, 1, 91. (b) Fujita, D.; Ueda, Y.; Sato, S.; Mizuno, N.; Kumasaka, T.; Fujita, M. Nature 2016, 540, 563. (c) Harris, K.; Fujita, D.; Fujita, M. Chem. Commun. 2013, 49, 6703.

(5) (a) Zhang, D.; Ronson, T. K.; Zou, Y.-Q.; Nitschke, J. R. Nat. Rev. Chem. 2021, 5, 168. (b) Yadav, S.; Kannan, P.; Qiu, G. Org. Chem. Front. 2020, 7, 2842. (c) Zhang, M.; Saha, M. L.; Wang, M.; Zhou, Z.; Song, B.; Lu, C.; Yan, X.; Li, X.; Huang, F.; Yin, S.; Stang, P. J. J. Am. Chem. Soc. 2017, 139, 5067. (d) Casini, A.; Woods, B.; Wenzel, M. Inorg. Chem. 2017, 56, 14715. (e) Wang, Q.-Q.; Gonell, S.; Leenders, S. H. A. M.; Dürr, M.; Ivanović-Burmazović, I.; Reek, J. N. H. Nat. Chem. 2016, 8, 225. (f) Brown, C. J.; Toste, F. D.; Bergman, R. G.; Raymond, K. N. Chem. Rev. 2015, 115, 3012. (g) Wang, J.; He, C.; Wu, P.; Wang, J.; Duan, C. J. Am. Chem. Soc. 2011, 133, 12402. (h) Mal, P.; Breiner, B.; Rissanen, K.; Nitschke, J. R. Science 2009, 324, 1697.

(6) (a) Dill, K. A.; MacCallum, J. L. Science 2012, 338, 1042. (b) Hartl, F. U.; Bracher, A.; Hayer-Hartl, M. Nature 2011, 475, 324.

(7) Seidel, S. R.; Stang, P. J. Acc. Chem. Res. 2002, 35, 972.

(8) Yoshizawa, M.; Catti, L. Acc. Chem. Res. 2019, 52, 2392.

(9) Lewis, J. E. M.; Crowley, J. D. ChemPlusChem 2020, 85, 815.

(10) (a) Tessarolo, J.; Lee, H.; Sakuda, E.; Umakoshi, K.; Clever, G. H. J. Am. Chem. Soc. 2021, 143, 6339. (b) Sudan, S.; Li, R.-J.; Jansze, S. M.; Platzek, A.; Rudolf, R.; Clever, G. H.; Fadaei-Tirani, F.; Scopelliti, R.; Severin, K. J. Am. Chem. Soc. 2021, 143, 1773. (c) Pullen, S.; Tessarolo, J.; Clever, G. H. Chem. Sci. 2021, 12, 7269. (d) Saha, S.; Holzapfel, B.; Chen, Y.-T.; Terlinden, K.; Lill, P.; Gatsogiannis, C.; Rehage, H.; Clever, G. H. J. Am. Chem. Soc. 2018, 140, 17384. (e) Pullen, S.; Clever, G. H. Acc. Chem. Res. 2018, 51, 3052. (f) Bloch, W. M.; Abe, Y.; Holstein, J. J.; Wandtke, C. M.; Dittrich, B.; Clever, G. H. J. Am. Chem. Soc. 2016, 138, 13750. (g) Kryschenko, Y. K.; Seidel, S. R.; Muddiman, D. C.; Nepomuceno, A. I.; Stang, P. J. J. Am. Chem. Soc. 2003, 125, 9647.

(11) (a) Lewis, J. E. M. Chem. Eur. J. 2021, 27, 4454. (b) Mishra, S. S.; Kompella, S. V. K.; Krishnaswamy, S.; Balasubramanian, S.; Chand, D. K. Inorg. Chem. 2020, 59, 12884. (c) Lisboa, L. S.; Findlay, J. A.; Wright, L. J.; Hartinger, C. G.; Crowley, J. D. Angew. Chem., Int. Ed.
2020, 59, 11101. (d) Lewis, J. E. M.; Tarzia, A.; White, A. J. P.; Jelfs, K. E. Chem. Sci. 2020, 11, 677. (e) Chen, B.; Horiuchi, S.; Holstein, J. J.; Tessarolo, J.; Clever, G. H. Chem. Eur. J. 2019, 25, 14921. (f) Preston, D.; Barnsley, J. E.; Gordon, K. C.; Crowley, J. D. J. Am. Chem. Soc. 2016, 138, 10578

(12) Liu, C.-L.; Bobylev, E. O.; Fu, Y.; Poole Iii, D. A.; Robeyns, K.; Fustin, C.-A.; Garcia, Y.; Reek, J. N. H.; Singleton, M. L. Chem. Eur. J. 2020, 26,11960

(13) Kerff, F.; Liu, C.-L.; Mu, X.; Gilbert, U.; Smal, L.; Meinertzhagen, L.; Kauffmann, B.; Robeyns, K.; Singleton, M. L. ChemPlusChem 2021, 86, 1162.

(14) (a) Jansze, S. M.; Cecot, G.; Wise, M. D.; Zhurov, K. O.; Ronson, T. K.; Castilla, A. M.; Finelli, A.; Pattison, P.; Solari, E.; Scopelliti, R.; Zelinskii, G. E.; Vologzhanina, A. V.; Voloshin, Y. Z.; Nitschke, J. R.; Severin, K. J. Am. Chem. Soc. 2016, 138, 2046. (b) Johnson, A. M.; Wiley, C. A.; Young, M. C.; Zhang, X.; Lyon, Y.; Julian, R. R.; Hooley, R. J. Angew. Chem., Int. Ed. 2015, 54, 5641. (c) Sun, Q. F.; Iwasa, J.; Ogawa, D.; Ishido, Y.; Sato, S.; Ozeki, T.; Sei, Y.; Yamaguchi, K.; Fujita, M. Science 2010, 328, 1144.

(15) Singleton, M. L.; Castellucci, N.; Massip, S.; Kauffmann, B.; Ferrand, Y.; Huc, I. J. Org. Chem. 2014, 79, 2115.

(16) (a) Fang, Y.; Powell, J. A.; Li, E.; Wang, Q.; Perry, Z.; Kirchon, A.; Yang, X.; Xiao, Z.; Zhu, C.; Zhang, L.; Huang, F.; Zhou, H.-C. Chem. Soc. Rev. 2019, 48, 4707. (b) Lee, J.; Farha, O. K.; Roberts, J.; Scheidt, K. A.; Nguyen, S. T.; Hupp, J. T. Chem. Soc. Rev. 2009, 38, 1450.

(17) (a) Bobylev, E. O.; Poole Iii, D. A.; de Bruin, B.; Reek, J. N. H. Chem. Sci. 2021, 12, 7696. (b) Jansze, S. M.; Cecot, G.; Wise, M. D.; Zhurov, K. O.; Ronson, T. K.; Castilla, A. M.; Finelli, A.; Pattison, P.; Solari, E.; Scopelliti, R.; Zelinskii, G. E.; Vologzhanina, A. V.; Voloshin, Y. Z.; Nitschke, J. R.; Severin, K. J. Am. Chem. Soc. 2016, 138, 2046.

(18) Morimoto, M.; Bierschenk, S. M.; Xia, K. T.; Bergman, R. G.; Raymond, K. N.; Toste, F. D. Nat. Catal. 2020, 3, 969.

(19) (a) He, L.; Li, H.; Chen, J.; Wu, X.-F. RSC Adv. 2014, 4, 12065. (b) Xu, Z.; Zhang, Y.; Fu, H.; Zhong, H.; Hong, K.; Zhu, W. Bioorg. Med. Chem. Lett. 2011, 21, 4005. (c) Chinigo, G. M.; Paige, M.; Grindrod, S.; Hamel, E.; Dakshanamurthy, S.; Chruszcz, M.; Minor, W.; Brown, M. L. J. Med. Chem. 2008, 51, 4620.

(20) (a) Tan, C.; Yang, K.; Dong, J.; Liu, Y.; Liu, Y.; Jiang, J.; Cui, Y. J. Am. Chem. Soc. 2019, 141, 17685. (b) Kharmawlong, G. K.; Nongrum, R.; Chhetri, B.; Rani, J. W. S.; Rahman, N.; Yadav, A. K.; Nongkhlaw, R. Synth. Commun. 2019, 49, 2683. (c) Jiao, J.; Li, Z.; Qiao, Z.; Li, X.; Liu, Y.; Dong, J.; Jiang, J.; Cui, Y. Nat. Commun. 2018, 9, 4423. (d) Rueping, M.; Antonchick, A. P.; Sugiono, E.; Grenader, K. Angew. Chem., Int. Ed. 2009, 48, 908.

(21) (a) C. Ngai, C. M. Sanchez-Marsetti, W. H. Harman, R. J. Hooley, Angew. Chem., Int. Ed., 2020, 59, 23505. (b) Holloway, L. R.; Bogie, P. M.; Lyon, Y.; Ngai, C.; Miller, T. F.; Julian, R. R.; Hooley, R. J. J. Am. Chem. Soc. 2018, 140, 8078. (c) Yang, J.; Chatelet, B.; Dufaud, V.; Hérault, D.; Michaud-Chevallier, S.; Robert, V.; Dutasta, J.-P.; Martinez, A. Angew. Chem., Int. Ed. 2018, 57, 14212. (d) Akiyama, T.; Mori, K. Chem. Rev. 2015, 115, 9277. (e) Shenoy, S. R.; Pinacho Crisostomo, F. R.; Iwasawa, T.; Rebek, J., Jr. J. Am. Chem. Soc. 2008, 130, 5658 


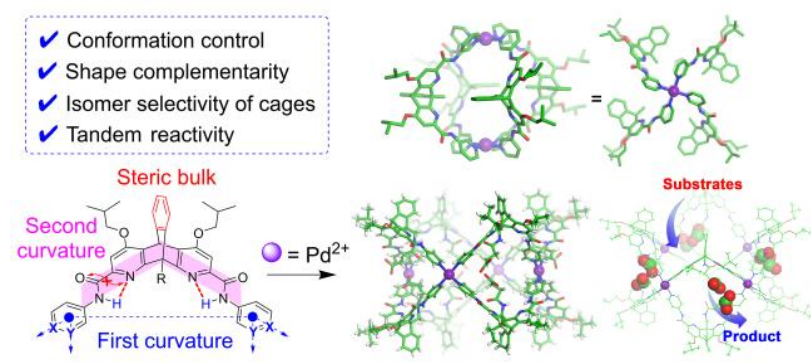

